\title{
An Infectious Disease and Mortality Survey in a Population of Free-Ranging African Wild Dogs and Sympatric Domestic Dogs
}

\author{
G. Flacke, ${ }^{1,2}$ P. Becker, ${ }^{3,4}$ D. Cooper, ${ }^{5}$ M. Szykman Gunther, ${ }^{3,6}$ I. Robertson, ${ }^{7}$ C. Holyoake, ${ }^{1}$ \\ R. Donaldson, ${ }^{1}$ and K. Warren ${ }^{1}$ \\ ${ }^{1}$ Conservation Medicine Program, College of Veterinary Medicine, School of Veterinary and Life Sciences, Murdoch University, \\ Perth, WA 6150, Australia \\ ${ }^{2}$ School of Animal Biology, University of Western Australia, 35 Stirling Highway, Crawley, WA 6009, Australia \\ ${ }^{3}$ Center for Species Survival, Smithsonian Conservation Biology Institute, National Zoological Park, Front Royal, VA 22630, USA \\ ${ }^{4}$ Centre for Wildlife Management, University of Pretoria, Pretoria 0002, South Africa \\ ${ }^{5}$ Ezemvelo KZN Wildife, Queen Elizabeth Park, Pietermaritzburg 3202, South Africa \\ ${ }^{6}$ Department of Wildlife, Humboldt State University, Arcata, CA 95521, USA \\ ${ }^{7}$ Veterinary Epidemiology Programme, College of Veterinary Medicine, School of Veterinary and Life Sciences, \\ Murdoch University, Perth, WA 6150, Australia
}

Correspondence should be addressed to G. Flacke; gflacke@hotmail.com

Received 3 November 2012; Revised 3 March 2013; Accepted 3 March 2013

Academic Editor: Antonio Terlizzi

Copyright (C) 2013 G. Flacke et al. This is an open access article distributed under the Creative Commons Attribution License, which permits unrestricted use, distribution, and reproduction in any medium, provided the original work is properly cited.

\begin{abstract}
Disease can cause declines in wildlife populations and significantly threaten their survival. Recent expansion of human and domestic animal populations has made wildlife more susceptible to transmission of pathogens from domestic animal hosts. We conducted a pathogen surveillance and mortality survey for the population of African wild dogs (Lycaon pictus) in KwaZulu-Natal (KZN), South Africa, from January 2006-February 2007. Samples were obtained from 24 wild dogs for canine distemper virus (CDV) and canine parvovirus (CPV) serological testing. Data were collected on the presence of CDV, CPV, and rabies virus in the KZN domestic dog (Canis familiaris) population from 2004-06. The presence of these pathogens was confirmed in domestic dogs throughout KZN. Wild dogs exhibited $0 \%$ and $4.2 \%$ prevalence for CDV and CPV antibodies, respectively. In 2006 the largest wild dog pack in KZN was reduced from 26 individuals to a single animal; disease due to rabies virus was considered the most probable cause. This study provides evidence that CDV, CPV and rabies are potential threats to African wild dog conservation in KZN. The most economical and practical way to protect wild dogs from canine pathogens may be via vaccination of sympatric domestic dogs; however, such programmes are currently limited.
\end{abstract}

\section{Introduction}

The impacts of infectious disease on wildlife populations and the importance of disease surveillance for endangered species conservation and management programmes have been repeatedly demonstrated [1-5]. The KwaZulu-Natal (KZN) African Wild Dog Reintroduction and Conservation Programme, in the South African province of KwaZuluNatal, has incorporated infectious pathogen and disease surveillance as one of many components within their longterm population monitoring strategy. The African wild dog is the most endangered carnivore in southern Africa, with just 3000-5700 individuals remaining [6, 7]. Across the continent, the total number of free-ranging African wild dogs is estimated at less than 8000 individuals, surviving in only 14 of their original 39 range countries [6-9]. In South Africa, the number of individuals is estimated to be only 300-400 $[6,7,10]$, and Kruger National Park currently contains the largest population with nearly half of the country's African wild dogs living within its boundaries.

The long-term goal of the KZN African Wild Dog Reintroduction and Conservation Programme is to establish a self-sustaining population of wild dogs in South Africa, specifically within KZN protected areas. As of 2006-2007 
when this study was conducted, the KZN population of 80 to 90 wild dogs accounted for approximately a quarter of South Africa's total population of this species [10]. Although the KZN wild dogs occur primarily within Hluhluwe-iMfolozi Park (HiP), the establishment of a viable population with adequate gene flow for outbreeding in this species requires the dispersal of individuals for maintenance of populationwide genetic diversity [11-13]. Due to land-use practices in KZN province, such dispersal requires movement between and among many small, separate protected areas and subpopulations. Disease risks are heightened during such dispersal events as contact with domestic dogs (Canis familiaris) may enable transmission of key threatening diseases to dispersing wild dogs $[5,14]$ and subsequently between their subpopulations. Unfortunately, long-term consequences of infectious pathogens for persistence of free-ranging African wild dog populations remain poorly understood and difficult to evaluate, due in part to a variety of interacting factors affecting disease dynamics [15].

Pathogens previously identified as a threat to African wild dogs, and thus of particular concern to the KZN African wild dog population, are canine distemper virus (CDV), canine parvovirus (CPV), and rabies virus [15]. The first of these, CDV, of the genus Morbillivirus, is the etiological agent of a contagious disease to which all carnivore species are susceptible, causing respiratory and central nervous system derangements [16]. CDV infection is usually more severe in immunologically naïve individuals and can reach epidemic proportions in immunologically naïve populations [17]. A number of documented outbreaks of CDV in African wild dogs across the continent indicate that the disease is of primary concern for the species, reducing long-term viability and increasing extinction risk for already small populations [18-21]. A single outbreak in a pack of wild dogs in South Africa's Tswalu Kalahari Reserve in 2005 resulted in the loss of the entire pack [22].

The second pathogen of concern, CPV, causes one of the most common and highly contagious infectious diseases of the domestic dog with clinical signs including haemorrhagic diarrhoea, emesis, dehydration, hypoproteinemia, and septicaemia [23]. Clinical disease resulting from CPV infection is often fatal, particularly in young pups, and all canids are susceptible [23]. Exposure followed by mild to no clinical signs of illness is more common in individuals exposed to the virus as adults; these animals still shed live viral particles and thus serve as a source of infection and environmental contamination [23]. Although CPV has not been considered as important a disease threat as CDV to endangered wild carnivores [24], it poses a major risk to small populations due to the potential for significant early pup mortality [25] and can negatively affect all age classes in immunologically naïve populations [26]. Seroprevalence to CPV among African wild dogs has been demonstrated across southern Africa [5], indicating that pathogen exposure does occur, albeit with unknown population-level impacts.

Rabies is an acute, fatal infection of the central nervous system by Lyssavirus spp. All mammals are considered susceptible, and while clinical signs of rabies can be extremely variable, they classically include acute behavioural alterations and pansystemic neurological dysfunction ranging from hyperesthesia, ataxia, paresis, and paralysis to tremors, seizures, and convulsions [27]. Rabies is considered a significant disease threat to the African wild dog across the continent and has been linked to the loss of entire packs, including the 1991 disappearances of all wild dog study packs from the Serengeti ecosystem in Tanzania [27-29]. Major confirmed rabies outbreaks in free-ranging African wild dogs also include those reported in the Masai Mara Reserve in Kenya [30, 31], Madikwe Game Reserve in South Africa [32, 33], and Etosha National Park in Namibia [34]. For the 1991 Serengeti outbreak, virus isolation and molecular diagnostics pointed to domestic dogs as the most probable source of rabies virus infection for the wild dogs [32]; diagnostic evidence collected during the 1989 Masai Mara outbreak suggested that the virus originated from domestic dogs living on the periphery of the reserve [30,31].

With human populations increasing in rural areas of KZN and throughout South Africa, more people are moving closer to the boundaries of game reserves, bringing with them various domestic animals. Across the continent, disease risks to wild dogs have been shown to increase dramatically in areas close to human habitation, as domestic dogs have the potential to serve as either a reservoir host or as a transmission source for many canine pathogens [35]. For the purposes of this study a reservoir is defined as a primary host that harbors the pathogen, demonstrates little to no ill effects, serves as a means of sustaining a pathogen in the environment, and serves as a source of infection for others. In Zimbabwe, Butler et al. [36] demonstrated that domestic dogs pose a direct risk for pathogen transmission to various wild carnivore species, including African wild dogs. In Kenya, Woodroffe et al. [14] followed 19 wild dog packs and found that exposure to rabies and CPV (but not $\mathrm{CDV}$ ) was associated with contact with domestic dogs. In $\mathrm{KZN}$, domestic dogs in rural community areas are unlikely to be vaccinated [37]. Since African wild dogs often cross out of protected areas during natural dispersal events and domestic dogs have been witnessed to range inside protected areas along park boundaries, there exists a substantial risk of contact between the two species. Wildlife poachers will also frequently bring domestic dogs into protected areas for hunting purposes.

The potential for contact between the KZN wild dogs and domestic dogs is of heightened concern because small populations of carnivore species living in fragmented habitats are particularly susceptible to population declines due to transmission of pathogens from larger populations of reservoir hosts [38, 39]. In such situations infectious pathogens can result in disease epidemics from which small, fragmented populations are unable to recover. For African wild dogs these population-level effects are exacerbated by pack structures and the highly social nature of the species. Further, even diseases with relatively low mortality rates or decreases in fecundity may provide sufficient additional loss to promote extinctions in small, declining, or fragmented populations [12]. Despite the apparent risks posed by infectious diseases, prior to our study period in 2006, there was no previous information available concerning the disease exposure status 
of African wild dogs in KZN province. The goals of this study were (1) to investigate the CDV and CPV status of the KZN wild dogs by serologically screening a representative proportion of the population (approximately 30\%), (2) to investigate the occurrence of CDV, CPV, and rabies in the KZN domestic dog population, and (3) to use this information to help develop management recommendations concerning the risks of these pathogens to the KZN African wild dog population.

\section{Materials and Methods}

2.1. Study Area, African Wild Dog Population, and Sample Collection. Serum samples and mortality information were collected from seven African wild dog packs in the KZN population $(n=24$; from a total population of approximately 70 individuals in 2006) between January 2006 and February 2007. Sampled individuals came from five packs in HluhluweiMfolozi Park $\left(28^{\circ} 4^{\prime} 59^{\prime \prime} \mathrm{S}, 32^{\circ} 4^{\prime} 59^{\prime \prime} \mathrm{E}\right)$, one pack in Mkuze Game Reserve $\left(27^{\circ} 37^{\prime} 59^{\prime \prime} \mathrm{S}, 32^{\circ} 15^{\prime} \mathrm{E}\right)$, and one pack in Thanda Private Game Reserve $\left(27^{\circ} 24^{\prime} \mathrm{S}, 32^{\circ} 9^{\prime} \mathrm{E}\right)$. Demographic data were available for all animals sampled in this study through the broader KZN African Wild Dog Reintroduction and Conservation Programme. This programme undertakes capture and chemical immobilization of wild dogs for telemetry collar attachment/removal and translocation between and within reserves; blood samples for this study were collected opportunistically during these immobilization procedures. Samples were collected in serum separator tubes and centrifuged within 24 hours of collection. The serum was frozen at $-20^{\circ} \mathrm{C}$ until analysis was conducted.

2.2. African Wild Dog Disease Analysis. All serological testing was conducted at the Department of Veterinary Tropical Diseases Laboratory, University of Pretoria, Onderstepoort campus. Serum antibodies reactive to canine distemper virus $(\mathrm{CDV})$ and canine parvovirus (CPV-2) were detected by means of an indirect fluorescent antibody technique as previously described [40]. Serum specimens were either screened at a serum dilution of $1: 20$ to minimize nonspecific fluorescence or titrated by testing serial twofold dilutions of sera. The CDV strain used in the preparation of the capture antigen slides was the Onderstepoort strain, while the CPV-2 strain was a field strain isolated from a clinically ill domestic dog in South Africa. Rabies serological assays were not conducted as part of this study, because all founding members of the KZN wild dog population and most wild dogs immobilized for management reasons had been vaccinated against rabies and because a positive rabies virus titre in an unvaccinated dog in the absence of clinical signs of rabies is extremely uncommon $[41,42]$.

2.3. Domestic Dog Data Collection. While the collection of blood samples from domestic dogs in KZN rural communities was outside the limits of this study, we used a variety of indirect methods to investigate the incidence or presence of CDV, CPV, and rabies in domestic dogs in KZN. For $\mathrm{CDV}$, we conducted 75 community disease surveys in rural Zulu communities near KZN protected areas and in dispersal corridors used by wild dogs to investigate for the presence of clinical signs of CDV. These surveys involved interviews conducted in Zulu, with unlabelled photographs of domestic dogs with clinical signs of the respiratory form of CDV for visual reference. Survey participants were asked if any of their household dogs had been observed in the past year with clinical signs similar to those in the photographs. Data from these surveys were used as a broad indication of disease prevalence of CDV in Zulu community dogs. The surveys also questioned interviewees about the number of dogs they owned, whether they used veterinary services, and the causes of death (if known) of any of their dogs which had died within the past year. CPV and rabies were not included in the surveys, as these two diseases do not present with "classical" clinical signs readily identifiable via photographs.

To further investigate for the presence of CDV and CPV in domestic dogs in areas near KZN protected areas, data on proportional disease rates of CDV and CPV in pet domestic dogs presenting to the practice during 2006 was obtained from five veterinarians with practices in towns surrounding the KZN protected areas. The proportional disease rate data is based on the number of cases seen at the practices, as established via presenting clinical signs and standard veterinary diagnostic methods. Although disease rates in these pet dogs were not expected to be exactly representative of disease status in rural Zulu community dogs, which are generally not vaccinated nor taken to private veterinarians, positive responses by local practitioners would confirm the presence of these diseases among the domestic dog population in areas covered by their practices.

To investigate rabies in domestic dogs, we obtained retrospective disease data from the KZN State Veterinary Authority (SVA), an organization which maintains data regarding all cases of reportable animal diseases. The data was reviewed to determine the number of reported canine rabies cases and estimated prevalence of canine rabies for 2004-2006 in the regions surrounding protected areas and in areas where wild dogs were known to disperse. The SVA also provided rabies vaccination information and domestic dog census data from 2001 onwards. These data on rabies cases and vaccine coverage in KZN would both represent minimums because, although the Veterinary Authority holds annual rabies vaccine campaigns in rural communities in $\mathrm{KZN}$, many areas are considered too difficult or dangerous to access. In addition, most community dogs are free-roaming semiferal animals which receive no veterinary attention outside of the vaccine campaigns and in which diseases usually go undetected and unreported.

2.4. African Wild Dog Mortality. We investigated age- and cause-specific mortality for the KZN population of African wild dogs from 01 January 2006 to 31 December 2006. An overall population mortality was calculated, along with ageand cause-specific mortalities, using data from all mortalities occurring during 2006. In addition to confirmed mortalities, any individual which disappeared from its pack and was not sighted within six months was considered deceased. All wild dogs are sighted frequently as part of the broader KZN Reintroduction and Conservation Programme, and to date there have been no individuals resighted after an absence of 
greater than six months. Given pack social structures and the likelihood that any wild dog dispersing into the rural, densely populated areas around parks would be reported, it was considered very unlikely that any disappearances were due to dispersal and ongoing survival outside KZN protected areas.

\section{Results}

3.1. African Wild Dog Serology. All sampled wild dogs $(n=24)$ exhibited negative titres for CDV, indicating $0 \%$ seroprevalence (95\% CI 0-11.7). One (1) of the 24 wild dogs exhibited a positive titre for CPV, representing $4.17 \%$ seroprevalence (95\% CI 0.1-21.1).

3.2. Community Surveys for CDV and Mortalities in Domestic Dogs. Of the $65 \mathrm{Zulu}$ households around HiP and in northern KZN which responded to interviews, 31\% $(n=20)$ households reported having 1-2 dogs, 35\% $(n=23)$ reported 3-4 dogs, and 34\% $(n=22)$ reported having more than five dogs. All interviewed households reported owning at least one dog. Very few households $(9 \% ; n=6)$ reported having taken their dogs to a private veterinarian.

Of interviewed households, $58 \%(n=38)$ reported the death of at least one of their dogs within the last year, with $26 \%$ of deaths attributed to illness, $21 \%$ to vehicle strike, $12 \%$ to attacks by other dogs, and $41 \%$ to unknown causes. When shown photographs of domestic dogs exhibiting clinical signs of the respiratory form of CDV, $8 \%(n=5)$ of households reported that at least one of their dogs had exhibited such clinical signs within the last year.

3.3. CDV and CPV in Domestic Dogs Presenting to Veterinary Clinics. In domestic dogs seen at the five private veterinary practices surrounding KZN protected areas during 2006, $1.7 \%$ (95\% CI 1.5-2.0\%) presented with CDV, and $1.7 \%$ (95\% CI 1.5-2.0\%) presented with CPV (D. Baxter-Vryheid; H. Kohrs-Pongola; N. Meunier-Hluhluwe; C. PrykeEshowe; T. Viljoen-Mtubatuba).

3.4. Rabies Cases and Vaccination Coverage from State Veterinary Authority Data. Annual observed incidence of rabies in domestic dogs in northern KZN, as contained in State Veterinary Authority records, was reported to range 17.4-18 (per 100000 animals) for 2004-2006 (Table 1) (KZN SVA, unpublished data). The SVA confirmed rabies-positive cases via indirect fluorescent antibody testing. Rabies vaccination coverage ranged $27.4 \%-30.8 \%$ over the same three years (Table 1), which represents between 100,000 and 120,000 dogs vaccinated among an estimated population of 365,000 to 390,000 dogs for the area in question (KZN SVA, unpublished data).

3.5. African Wild Dog Mortality. During 2006 the KZN wild dog population lost 53 of 70 individuals (including confirmed mortalities and permanent disappearances). The overall mortality was $75.7 \%$ during 2006 (Table 2). The highest proportion of mortalities was attributed to "suspected disease" (37.7\% of cases; Table 2), followed by snaring
TABLE 1: Rabies prevalence and rabies vaccination coverage data for domestic dogs in northern KZN for 2004, 2005, and 2006, from State Veterinary Authority records. Annual observed incidence is presented as a combined value per 100,000 animals for all districts for each year.

\begin{tabular}{ccc}
\hline Year & $\begin{array}{c}\text { Annual observed incidence } \\
\text { (per 100,000 animals) }\end{array}$ & Average vaccination coverage \\
\hline 2004 & $17.4 /$ year & $30.8 \%$ \\
2005 & $18.0 /$ year & $28.9 \%$ \\
2006 & $18.0 /$ year & $27.4 \%$ \\
\hline
\end{tabular}

(13.2\% of cases). In $32.1 \%$ of cases the cause of death was unknown, although this included at least one individual strongly suspected to have been killed by lions or hyenas, having disappeared overnight from its pack, with fresh tracks of multiple lions and hyenas observed the following day at the pack's overnight resting site. The "Other" category included two individuals apparently killed by crocodiles (they both disappeared immediately after chasing a prey animal into the Hluhluwe River, which is densely populated by crocodiles) and one individual which died secondary to an anaesthetic reaction during a routine immobilization procedure.

3.6. Loss of the iMfolozi Pack: Observations Suggest Disease as the Cause. Twenty of 26 wild dogs from KZN's largest pack, the iMfolozi pack, were lost in a period of less than 2 months in August/September of 2006 (11 adults/yearlings and all nine of the pack's pups). By mid-2007, five of the remaining six animals had disappeared, and only the alpha female remained. No carcasses could be recovered for diagnostic testing because the pack's only radiocollared animal was the second animal to disappear, and his carcass was severely decomposed when retrieved. However, several pieces of anecdotal evidence support disease as a primary factor associated with the pack's disappearance: (1) the short time in which such a large number of animals were lost is highly consistent with disease and highly inconsistent with other common causes of death in wild dogs (i.e., snaring or predation); (2) the pack denned on the south-western boundary of the reserve, a location where wild dogs were often observed to cross in and out of the park; (3) domestic dogs were observed inside the park in this area; (4) a domestic dog was observed feeding with the iMfolozi pack on a carcass in July 2006 (this dog was destroyed, but no disease testing was conducted); (5) within one month of the observation of the domestic dog feeding with the iMfolozi pack, a yearling member of the pack was observed exhibiting clinical signs consistent with either rabies or the neurological form of CDV (emaciated, weakness, and ataxia), and within two months a large majority of the pack had disappeared; (6) over the same two-month period there was a focal epidemic of rabies in domestic dogs near the south-western boundary of the park where the iMfolozi pack denned including a confirmed case less than $20 \mathrm{~km}$ from the den site where the pack was known to cross in and out of reserve boundaries [43]; (7) the surviving alpha female was one of only two pack members to have ever received a rabies vaccination (six years previously); 
TABLE 2: Cause-specific mortality (\%) for 12 pups and 41 adults/yearlings in the KZN population of African wild dogs for 2006 . The overall population mortality for 2006 is also presented. The "unknown" category includes both animals confirmed to have died and animals which disappeared and were never resighted (minimum 6 months).

\begin{tabular}{lccc}
\hline 2006 & Pups $(n=12)$ & Adults/yearlings $(n=41)$ & Total $(n=53)$ \\
\hline Overall mortality $(53 / 70)$ & & & $75.71 \%$ \\
Snaring & $0.0 \%$ & $17.07 \%(n=7)$ & $13.20 \%$ \\
Lion predation/attack & $16.67 \%(n=2)$ & $4.88 \%(n=2)$ & $7.55 \%$ \\
Old age & $0.0 \%$ & $4.88 \%(n=2)$ & $3.77 \%$ \\
Suspected disease & $75.0 \%(n=9)$ & $26.83 \%(n=11)$ & $37.74 \%$ \\
Other & $0.0 \%$ & $7.32 \%(n=3)$ & $5.66 \%$ \\
Unknown & $8.33 \%(n=1)$ & $39.02 \%(n=16)$ & $32.08 \%$ \\
\hline
\end{tabular}

the other previously vaccinated animal was the radiocollared alpha male.

\section{Discussion}

The loss of 53 African wild dogs in a single year from a population of only around 70 individuals is clearly unsustainable and is markedly higher than mortality rates reported for other African wild dog populations [24, 44-46]. We note that the loss of the iMfolozi pack contributed substantially to the mortality total and that this loss was suspected to be linked to a disease epidemic. Given the lack of other confirmed or suspected disease epidemics during 10 years of demographic research at KZN, the 2006 mortality rate does not reflect the average annual mortality rate for the population. However, even when excluding the iMfolozi pack losses from the mortality tally ( $n=20$ by the end of 2006), a loss of 33 of 70 animals in a single year is still highly unsustainable for a small population.

The unsustainable mortality rate lends extra significance to a large number of deaths suspected to be caused by disease in KZN wild dogs. In addition to the $37.7 \%$ of deaths linked directly to the suspected rabies outbreak (the loss of the iMfolozi pack), disease cannot be ruled out as an underlying factor in other wild dog deaths in 2006. Several wild dogs were confirmed predator kills, and multiple "unknown" and "other" mortalities were strongly suspected to be due to hyena, lion, and crocodile attacks. Although not listed as a known cause of mortality for 2006, trauma secondary to motor vehicle collision is also a relatively frequent cause of mortality for the KZN wild dog population due to the presence of the Corridor Road, a two-lane paved commercial road bisecting HiP. Wild dogs will be more likely to be subject to predation or vehicle collisions when they are weakened by an underlying subclinical or ongoing chronic disease.

Consistent with Prager et al. [5], which included samples shared from our study, we found a low to zero prevalence of antibodies to CDV and CPV in the animals sampled. We caution that these findings are concerning given the presence of these pathogens in sympatric domestic dogs and the severe consequences of these infectious diseases for small, immunologically naïve populations. The wild dog which tested positive for CPV antibodies in this study is likely to have been exposed to CPV before arriving in $\mathrm{KZN}$, as the animal was translocated to HiP in February 2006 from
Limpopo province and was sampled upon arrival in $\mathrm{HiP}$. Excluding this new arrival, the prevalence of CDV and CPV antibodies among sampled individuals originating from KZN was $0 \%$. In domestic dogs, serum antibody titres to $\mathrm{CPV}$ are known to remain high for years after exposure, even in the absence of reexposure [23], and while it is not known whether nondomestic canids have a similar immunological response, a detectable CPV titre would be expected in adult pack members who had been exposed to CPV as pups or juveniles. The negative results may therefore indicate either a lack of CPV exposure to date or $100 \%$ mortality for all exposed/infected animals for this population.

There are several reasons to remain vigilant in the face of these CDV and CPV results: (1) although no CDV exposure was detected, the $95 \%$ confidence intervals for CDV seroprevalence indicate that the actual prevalence could still be as high as $11.73 \%$ in the total population; (2) the finding of $0 \% \mathrm{CDV}$ seroprevalence could indicate that exposed wild dogs do not survive infection, which may be the case if the viral strain is highly pathogenic, particularly since immunologically naïve animals are more susceptible to severe disease; (3) private veterinarians confirmed the presence of both CDV and CPV among pet dogs presenting to clinics in areas around KZN protected areas; (4) communal area surveys indicated that $26 \%$ of dog deaths in the past year were attributed by their owners to disease and that $8 \%$ of owners reported one or more dogs with clinical signs consistent with CDV infection; (5) African wild dogs and domestic dogs are both confirmed to cross boundaries between protected and community areas in $\mathrm{KZN}$, and direct contact between individuals of both species was observed in KZN in 2006 by one of this paper's authors (P. Becker).

Reports from other populations of African wild dogs demonstrate the capacity of CDV to cause rapid extinction of packs or local populations. In Tswalu Kalahari Reserve (Northern Cape Province, South Africa) a confirmed CDV outbreak resulted in $100 \%$ mortality in a pack of nine wild dogs over a one-month period in 2005 [22]. In Chobe National Park, Botswana, CDV similarly resulted in the local extinction of a small pack of resident African wild dogs in 1994. As with all infectious pathogens, CDV risks are particularly high for small, fragmented populations [38, 47]. A population of African wild dogs from the Okavango Delta, Botswana, showed high seroprevalence of CDV without 
associated reduction in pup survivorship or increased adult mortality [15], possibly indicating exposure to a CDV strain of lower virulence and resulting in long-lasting immunity for this population. Interestingly, in 1996 this same Okavango wild dog population also experienced a substantial loss of individuals (five packs over a 4-week period), similar to that which occurred for the iMfolozi pack in our study; CDV or rabies was hypothesized to be the ultimate cause, but no carcases could be recovered for confirmation [15].

CPV infections among wild dogs in Selous Game Reserve (Tanzania) were hypothesized to be responsible for significant reductions in litter size before den emergence [24]. The introduction of CPV into immunologically naïve populations, such as the KZN population, could potentially increase pup mortality during subsequent denning seasons, precipitating population decline. Indeed, Barker and Parrish [26] warn that, for small, isolated populations, the establishment of CPV as an endemic disease with ongoing reductions in pup recruitment would have substantial impacts on population survival. Another concern for CPV is the highly persistent nature of this pathogen in the environment, with viral particles remaining infectious for months to years depending on environmental conditions [23]. Prager et al. [5] demonstrated high prevalence of CPV antibodies in wild dogs with limited to not known domestic dog contact, an indication that due to prolonged pathogen persistence in the environment CPV may become self-perpetuating in small wildlife populations even in the absence of a domestic dog reservoir.

Rabies has repeatedly shown to pose a significant threat to wild dog conservation [28, 30, 31, 47]. Although not directly investigated via serology for African wild dogs in this study, the presence of rabies in domestic dogs in northern KZN during 2004-2006 was confirmed by State Veterinary Authority records, including in communities bordering protected areas inhabited by wild dogs. There were likely many undocumented rabies cases among domestic dogs in KZN during this time period, given the fact that less than onethird of communal areas were visited during annual rabies vaccination campaigns and only $9 \%$ of surveyed households reported taking their dogs to veterinarians. Prevalence of rabies is described to be grossly underestimated in KZN due to a high level of underreporting of cases, both in domestic animals and humans [37].

The domestic dog rabies epidemic in the Ntambanana district at the south-western border of HiP during 2006 occurred over the same 2-month period when 20 out of 26 wild dogs were lost from the iMfolozi pack just inside the park, including confirmation of death for the only radiocollared pack member. Clinical signs consistent with rabies were observed in another animal before it disappeared, within one month of the pack being observed feeding on a kill with a domestic dog inside park borders at the start of the rabies outbreak. These observations are consistent with rabies being the probable cause of mortalities for the iMfolozi pack, particularly given the highly contagious nature of the virus, the ease with which rabies could be transmitted between pack members due to close social interactions [47], and the rapid mortality rates observed in other African wild dog packs infected with rabies $[30,32,48]$. The case for disease as the cause of mortality is strengthened by the lack of a convincing alternative explanation, given that the other known common causes of mortality for KZN wild dogs (snaring, predation, and vehicle strike) would be highly unlikely to result in the loss of so many pack members in such a short time frame. Additionally, it is of interest that the sole surviving pack member identified in mid-2007 was one of only two pack members that had been previously vaccinated against rabies. However, the vaccine was administered six years earlier, and the individual never received a booster vaccine; the efficacy of a single rabies vaccination in preventing mortality after exposure to the virus has been variable in previous reports $[32,33,48,49]$.

Vaccination of African wild dogs against infectious disease is usually not considered a viable management option given that most vaccines need to be administered parenterally on an annual or triannual basis. Hofmeyr et al. [33] reported that although rabies vaccination can have a beneficial impact in the face of a disease epidemic, multiple doses may be needed to ensure protection. Vial et al. [50] advocate that rabies vaccination of a "core" population of $30-40 \%$ of wild dogs in small populations every $1-2$ years would theoretically be effective at controlling rabies and thus ensuring wild dog persistence. However, the efficacy and duration of immunity of domestic dog vaccine products in African wild dogs is largely unknown [50]. Inactivated CDV vaccines generally do not stimulate adequate seroconversion or protective immunity in nondomestic carnivore species [51]. At least one study has demonstrated that modified-live CDV vaccines designed for use in domestic dogs can induce seroconversion in captive African wild dogs [52], but seroconversion does not necessarily guarantee protective immunity against disease. There are several instances in which modified-live CDV vaccines have been used in this species without complications [52-54]; however, modified-live CDV vaccines also have the potential to cause mortality in this species, most probably through reversion to virulence and as a result of host immune system differences [55-57].

Given these various limitations, complexities, and concerns about vaccination in wildlife populations as a disease control strategy, the most economical and practical way to protect wild dogs from exposure to key canine pathogens may be via vaccination and control of domestic dog populations in areas adjacent to protected areas where wild dogs reside. It is generally reported that a vaccine coverage threshold of $70 \%$ is required in order to eliminate rabies as a disease threat from any given population [58-61]. In northern KZN the overall rabies vaccination coverage for domestic dogs is far below this threshold at approximately $30 \%$. In contrast to many other parts of southern Africa, KZN does not have a significant wildlife reservoir of rabies; rather the primary rabies host species is the domestic dog $[43,62]$. Therefore control or eradication of rabies in domestic dogs, including semiferal community dogs, has the potential to control or eliminate rabies as a threat to African wild dogs and other wildlife in the region [14]. A recent study reported that vaccination of domestic dogs in Tanzania is a feasible option for canine rabies control and thus also rabies control in sympatric wildlife [61]. 
Unfortunately, there are many reasons why domestic dog vaccination campaigns in northern KZN do not achieve adequate vaccine coverage in rural community areas, including difficulty accessing many communities due to poor road infrastructure and safety concerns, lack of funding for staff and supplies for larger-scale vaccine campaigns, opinions of local people regarding administration of pharmaceuticals to their animals, and political pressures placed on state veterinary authorities to concentrate efforts on other highprofile domestic livestock diseases. These challenges are not unique to KZN; Alexander et al. [15] as well as Prager et al. [39] outline the many complications inherent in attempting to manage disease risks in African wild dog populations by focussing on controlling disease in the reservoir host(s). In situations where it is not feasible to manage disease in the domestic dog pathogen host, the vaccination of African wild dogs may be the only viable option to limit the risk of widespread disease. Pathogen control via vaccination of key pack members and more vulnerable packs (e.g., those located in edge habitats) could function as an alternative control strategy $[39,50]$ and could be considered for the KZN African wild dog population.

In conclusion, the data and information presented indicate that infectious diseases, especially those with broad host ranges, such as CDV, CPV, and rabies, are a conservation concern for the African wild dog both in South Africa and across the continent. Mortality data and field observations in this study strongly suggest that infectious disease was the major cause of mortality in the KZN African wild dog population for 2006. Additionally, CDV, and CPV were found to be present in the geographically sympatric domestic dog population and thus could pose a threat in the future, especially as previous exposure (as measured via serology) and hence immune system competence against these diseases were low to nonexistent in the KZN African wild dog population. To reduce infectious disease risk for this population, wildlife managers need to further explore bolstering sympatric domestic dog vaccination campaigns and consider vaccinating key packs or a strategic number of key pack members. Pathogen management strategies must be implemented in combination with management of other threats to wild dog survival, including continued habitat fragmentation and landscape-associated factors limiting natural dispersal events.

\section{Abbreviations}

CDV: Canine distemper virus

CI: Confidence interval

CPV: Canine parvovirus

KZN: KwaZulu-Natal

$n$ : Sample size.

\section{Acknowledgments}

The authors wish to thank the management of HluhluweiMfolozi Park, the Isimangaliso (Greater St. Lucia) Wetland Park Authority, Mkuze Game Reserve, and Thanda Private Game Reserve for permission to conduct this research and for logistical support. They also thank the Ezemvelo KZN Wildlife Game Capture Unit for use of laboratory and darting equipment. They are grateful to the private and state veterinarians who kindly provided data regarding disease and vaccinations in domestic dogs: Drs. G. Archibald, R. Bagnall, D. Baxter, H. Kohrs, N. Meunier, C. Pryke, and T. Viljoen. They are also grateful to Gus van Dyk, wildlife manager of the Tswalu Kalahari Reserve, for information regarding CDV in African wild dogs. They thank Dr. Moritz van Vuuren and the laboratory at Department of Veterinary Tropical Diseases, Onderstepoort, for conducting the serology for this project. Finally, they wish to thank Sboniso "Zama" Zwane for assistance with field monitoring and for conducting disease surveys in Zulu communities and Thadaigh Baggallay for assistance with field monitoring. This project was supported by the National Geographic Society Conservation Trust (Grant no. C91-06) and the Conservation Medicine Small Research Grants Program at Murdoch University.

\section{References}

[1] P. Daszak, A. A. Cunningham, and A. D. Hyatt, "Anthropogenic environmental change and the emergence of infectious diseases in wildlife," Acta Tropica, vol. 78, no. 2, pp. 103-116, 2001.

[2] D. Spielman, "The roles of contagious diseases in natural populations, endangered populations, captive populations, and in wildlife breeding, translocation and rehabilitation programmes," in Veterinary Conservation Biology Wildlife Health and Management in Australasia, Proceedings of the International Joint Conference of World Association of Wildlife Veterinarians, A. Martin and L. Vogelnest, Eds., pp. 205-210, Wildlife Disease Association: Australasian Section, Australian Association of Veterinary Conservation Biologists and Wildlife Society of the New Zealand Veterinary Association, Australasian Veterinary Association, Sydney, Australia, 2001.

[3] L. Munson and W. Karesh, "Disease monitoring for the conservation of terrestrial animals," in Conservation MedicIne: Ecological Health In Practice, A. A. Aguirre, G. M. Tabor, M. C. Pearl, R. S. Ostfeld, and C. House, Eds., pp. 95-102, Oxford University Press, Oxford, UK, 2002.

[4] D. A. Randall, J. Marino, D. T. Haydon et al., "An integrated disease management strategy for the control of rabies in Ethiopian wolves," Biological Conservation, vol. 131, no. 2, pp. 151-162, 2006.

[5] K. C. Prager, J. A. K. Mazet, L. Munson et al., "The effect of protected areas on pathogen exposure in endangered African wild dog (Lycaon pictus) populations," Biological Conservation, vol. 150, pp. 15-22, 2012.

[6] R. Woodroffe, J. W. McNutt, and M. G. L. Mills, "African wild dog," in Foxes, Wolves, Jackals and Dogs: Status Survey and Conservation Action Plan, C. Sillero-Zubiri and D. W. MacDonald, Eds., pp. 174-183, IUCN, Gland, Switzerland, 2nd edition, 2004.

[7] IUCN/SSC, Regional Conservation Strategy for the Cheetah and African Wild Dog in Southern Africa, I.S.S. Commission, Gland, Switzerland, 2007.

[8] Kenya Wildlife Service, Proposal for Inclusion of Species on the Appendices of the Convention of the Conservation of Migratory Species of Wild Animals, Kenya Wildlife Service, Nairobi, Kenya, 2010, http://www.cms.int/bodies/COP/cop9/proposals/Eng/II_ 5_Lycaon_pictus_KEN_E.pdf. 
[9] IUCN/SSC, Regional Conservation Strategy for the Cheetah and Wild Dog in Eastern Africa, I.S.S. Commission, Gland, Switzerland, 2008.

[10] H. T. Davies-Mostert, M. G. L. Mills, and D. W. MacDonald, "A critical assessment of South Africa's managed metapopulation recovery strategy for African wild dogs," in ReIntroduction of Top-Order Predators, M. W. Hayward and M. J. Somers, Eds., pp. 10-42, Wiley-Blackwell, London, UK, 2009.

[11] T. K. Fuller, M. G. L. Mills, M. Borner, M. K. Laurenson, and P. W. Kat, "Long distance dispersal by African wild dogs in East and South Africa," Journal of African Zoology, vol. 106, pp. 535537, 1992.

[12] S. Creel and N. M. Creel, "Six ecological factors that may limit African wild dogs, Lycaon pictus," Animal Conservation, vol. 1, no. 1, pp. 1-9, 1998.

[13] K. A. Leigh, K. R. Zenger, I. Tammen, and H. W. Raadsma, "Loss of genetic diversity in an outbreeding species: small population effects in the African wild dog (Lycaon pictus)," Conservation Genetics, vol. 13, pp. 767-777, 2012.

[14] R. Woodroffe, K. C. Prager, L. Munson, J. Conrad, E. J. Dubovi, and J. A. K. Mazet, "Contact with domestic dogs increases pathogen exposure in endangered African wild dogs (Lycaon pictus)," PLoS One, vol. 7, pp. 1-9, 2012.

[15] K. A. Alexander, J. W. McNutt, M. B. Briggs et al., "Multihost pathogens and carnivore management in southern Africa," Comparative Immunology, Microbiology and Infectious Diseases, vol. 33, no. 3, pp. 249-265, 2010.

[16] S. L. Deem, L. H. Spelman, R. A. Yates, and R. J. Montali, "Canine distemper in terrestrial carnivores: a review," Journal of Zoo and Wildlife Medicine, vol. 31, no. 4, pp. 441-451, 2000.

[17] C. E. Greene and M. J. G. Appel, "Canine distemper virus," in Infectious Diseases of the Dog and Cat, C. E. Green, Ed., pp. 2541, Elsevier, St. Louis, Miss, USA, 3rd edition, 2006.

[18] K. A. Alexander and M. J. Appel, "African wild dogs (Lycaon pictus) endangered by a canine distemper epizootic among domestic dogs near the Masai Mara National Reserve, Kenya," Journal of wildlife diseases, vol. 30, no. 4, pp. 481-485, 1994.

[19] K. A. Alexander, P. W. Kat, L. A. Munson, A. Kalake, and M. J. G. Appel, "Canine distemper-related mortality among wild dogs (Lycaon pictus) in Chobe National Park, Botswana," Journal of Zoo and Wildlife Medicine, vol. 27, no. 3, pp. 426-427, 1996.

[20] M. W. G. Van De Bildt, T. Kuiken, A. M. Visee, S. Lema, T. R. Fitzjohn, and A. D. M. E. Osterhaus, "Distemper outbreak and its effect on African wild dog conservation," Emerging Infectious Diseases, vol. 8, no. 2, pp. 211-213, 2002.

[21] K. V. Goller, R. D. Fyumagwa, V. Nikolin et al., "Fatal canine distemper infection in a pack of African wild dogs in the Serengeti ecosystem, Tanzania," Veterinary Microbiology, vol. 146, no. 3-4, pp. 245-252, 2010.

[22] G. van Dyk, Wildlife Manager of the Tswalu Kalahari Reserve, personal communication, 2007.

[23] D. McCaw and J. Hoskins, "Canine viral enteritis," in Infectious Diseases of the Dog and Cat, C. E. Greene, Ed., pp. 63-73, Elsevier, St. Louis, Miss, USA, 3rd edition, 2006.

[24] S. Creel, N. M. Creel, L. Munson, D. Sanderlin, and M. J. G. Appel, "Serosurvey for selected viral diseases and demography of African wild dogs in Tanzania," Journal of Wildlife Diseases, vol. 33, no. 4, pp. 823-832, 1997.

[25] L. D. Mech and S. M. Goyal, "Effects of canine parvovirus on gray wolves in Minnesota," Journal of Wildlife Management, vol. 59, no. 3, pp. 565-570, 1995.
[26] I. K. Barker and C. R. Parrish, "Parvovirus infections," in Infectious Diseases of Wild Mammals, E. S. Williams and I. K. Barker, Eds., pp. 131-146, Iowa State Press, Ames, Iowa, USA, 3rd edition, 2001.

[27] C. E. Rupprecht, K. Stoehr, and C. Meredity, "Rabies," in Infectious Diseases of Wild Mammals, S. Williams and I. K. Barker, Eds., pp. 3-36, Iowa State Press, Ames, Iowa, USA, 3rd edition, 2001.

[28] S. C. Gascoyne, M. K. Laurenson, S. Lelo, and M. Borner, "Rabies in African wild dogs (Lycaon pictus) in the Serengeti region, Tanzania," Journal of Wildlife Diseases, vol. 29, no. 3, pp. 396-402, 1993.

[29] D. W. Macdonald, M. Artois, M. Aubert et al., "Cause of wild dog deaths," Nature, vol. 360, pp. 633-634, 1992.

[30] K. A. Alexander, J. D. Richardson, L. Munson, and P. W. Kat, "An outbreak of rabies among African wild dogs (Lycaon pictus) in the Masai Mara, Kenya," in Proceedings of the American Association of Zoo Veterinarians, p. 340, St. Louis, Miss, USA, 1993.

[31] P. W. Kat, K. A. Alexander, J. S. Smith, and L. Munson, "Rabies and African wild dogs in Kenya," in Proceedings of the Royal Society of London B Biological Sciences, vol. 262, pp. 229-233, 1995.

[32] M. Hofmeyr, J. Bingham, E. P. Lane, A. Ide, and L. Nel, "Rabies in African wild dogs (Lycaon pictus) in the Madikwe Game Reserve, South Africa," Veterinary Record, vol. 146, no. 2, pp. 5052, 2000.

[33] M. Hofmeyr, D. Hofmeyr, L. Nel, and J. Bingham, "A second outbreak of rabies in African wild dogs (Lycaon pictus) in Madikwe Game Reserve, South Africa, demonstrating the efficacy of vaccination against natural rabies challenge," Animal Conservation, vol. 7, no. 2, pp. 193-198, 2004.

[34] J. L. Scheepers and K. A. E. Venzke, "Attempts to reintroduce African wild dogs Lycaon pictus into Etosha National Park, Namibia," South African Journal of Wildlife Research, vol. 25, pp. 138-140, 1995.

[35] R. Woodroffe and J. R. Ginsberg, "Past and future causes of wild dogs' population decline," in The African Wild Dog: Status, Survey, and Conservation Action Plan, R. Woodroffe, J. R. Ginsberg, and D. W. MacDonald, Eds., pp. 58-74, IUCN, Gland, Switzerland, 1997.

[36] J. R. A. Butler, J. T. Du Toit, and J. Bingham, "Free-ranging domestic dogs (Canis familiaris) as predators and prey in rural Zimbabwe: threats of competition and disease to large wild carnivores," Biological Conservation, vol. 115, no. 3, pp. 369-378, 2004.

[37] N. Meunier, State Veterinarian, Hlabisa District, Personal Communication, 2006.

[38] S. M. Funk, C. V. Fiorello, S. Cleaveland, and M. E. Gompper, "The role of disease in carnivore ecology and conservation," in Carnivore Conservation, J. L. Gittleman, S. M. Funk, D. W. MacDonald, and R. K. Wayne, Eds., pp. 443-466, Cambridge University Press, Cambridge, UK, 2001.

[39] K. C. Prager, R. Woodroffe, A. Cameron, and D. T. Haydon, "Vaccination strategies to conserve the endangered African wild dog (Lycaon pictus)," Biological Conservation, vol. 144, no. 7, pp. 1940-1948, 2011.

[40] M. Van Vuuren, "Serological studies of bovine respiratory syncytial virus in feedlot cattle in South Africa," Journal of the South African Veterinary Association, vol. 61, no. 4, pp. 168-169, 1990. 
[41] J. F. Bell, M. A. Gonzales, A. M. Diaz, and G. J. Moore, "Nonfatal rabies in dogs-experimental studies and results of a survey," American Journal of Veterinary Research, vol. 32, pp. 2049-2058, 1971.

[42] M. Fekudo and J. H. Shaddock, "Peripheral distribution of virus in dogs inoculated with two strains of rabies virus," American Journal of Veterinary Research, vol. 45, pp. 724-729, 1984.

[43] R. Bagnall, KZN State Veterinary Authority, Personal Communication, 2006.

[44] J. Van Heerden, M. G. Mills, M. J. Van Vuuren, P. J. Kelly, and M. J. Dreyer, "An investigation into the health status and diseases of wild dogs (Lycaon pictus) in the Kruger National Park," Journal of the South African Veterinary Association, vol. 66, no. 1, pp. 18-27, 1995.

[45] J. R. Ginsberg, K. A. Alexander, S. Creel, P. W. Kat, J. W. McNutt, and M. G. Mills, "Handling and survivorship of African wild $\operatorname{dog}$ (Lycaon pictus) in five ecosystems," Conservation Biology, vol. 9, no. 3, pp. 665-674, 1995.

[46] R. Woodroffe, H. Davies-Mostert, J. Ginsberg et al., "Rates and causes of mortality in Endangered African wild dogs Lycaon pictus: lessons for management and monitoring," Oryx, vol. 41, no. 2, pp. 215-223, 2007.

[47] M. G. Mills, "Social systems and behaviour of the African wild dog Lycaon pictus and the spotted hyaena Crocuta crocuta with special reference to rabies," Onderstepoort Journal of Veterinary Research, vol. 60, no. 4, pp. 405-409, 1993.

[48] R. Woodroffe, "Assessing the risks of intervention: immobilization, radio-collaring and vaccination of African wild dogs," Oryx, vol. 35, no. 3, pp. 234-244, 2001.

[49] D. L. Knobel, A. Liebenberg, and J. T. Du Toit, "Seroconversion in captive African wild dogs (Lycaon pictus) following administration of a chicken head bait/SAG-2 oral rabies vaccine combination," Onderstepoort Journal of Veterinary Research, vol. 70, no. 1, pp. 73-77, 2003.

[50] F. Vial, S. Cleaveland, G. Rasmussen, and D. T. Haydon, "Development of vaccination strategies for the management of rabies in African wild dogs," Biological Conservation, vol. 131, no. 2, pp. 180-192, 2006.

[51] R. J. Montali, C. R. Bartz, J. A. Teare, J. T. Allen, M. J. Appel, and M. Bush, "Clinical trials with canine distemper vaccines in exotic carnivores," Journal of the American Veterinary Medical Association, vol. 183, no. 11, pp. 1163-1167, 1983.

[52] J. van Heerden, J. Bingham, M. van Vuuren, R. E. J. Burroughs, and E. Stylianides, "Clinical and serological response of wild dogs (Lycaon pictus) to vaccination against canine distemper, canine parvovirus infection and rabies," Journal of the South African Veterinary Association, vol. 73, no. 1, pp. 8-12, 2002.

[53] J. Spencer and R. Burroughs, "Antibody response to canine distemper vaccine in African wild dogs," Journal of Wildlife Diseases, vol. 28, no. 3, pp. 443-444, 1992.

[54] J. Van Heerden, W. H. Swart, and D. G. A. Meltzer, "Serum antibody levels before and after administration of live canine distemper vaccine to the wild dog Lycaon pictus," Journal of the South African Veterinary Association, vol. 51, no. 4, pp. 283-284, 1980.

[55] A. E. McCormick, "Canine distemper in African hunting dogs (Lycaon pictus) - possibly vaccine induced," The Journal of Zoo Animal Medicine, vol. 14, pp. 66-71, 1983.

[56] J. Van Heerden, N. Bainbridge, R. E. Burroughs, and N. P. Kriek, "Distemper-like disease and encephalitozoonosis in wild dogs (Lycaon pictus)," Journal of Wildlife Diseases, vol. 48, pp. 19-21, 1989.
[57] B. Durchfeld, W. Baumgärtner, W. Herbst, and R. Brahm, "Vaccine-associated canine distemper infection in a litter of African hunting dogs (Lycaon pictus)," Zentralblatt für Veterinärmedizin Reihe B, vol. 37, no. 3, pp. 203-212, 1990.

[58] P. G. Coleman and C. Dye, "Immunization coverage required to prevent outbreaks of dog rabies," Vaccine, vol. 14, pp. 185-186, 1996.

[59] WHO, "WHO Expert Consultation on Rabies," Technical Report Series 931, World Health Organization, 2005.

[60] J. F. Reece and S. K. Chawla, "Control of rabies in Jaipur, India, by the sterilisation and vaccination of neighbourhood dogs," Veterinary Record, vol. 159, no. 12, pp. 379-383, 2006.

[61] M. C. Fitzpatrick, K. Hampson, S. Cleaveland, L. Ancel Meyers, J. P. Townsend, and A. P. Galvani, "Potential for rabies control through dog vaccination in wildlife-abundant communities of Tanzania," PLoS Neglected Tropical Diseases, vol. 6, no. 8, Article ID e1796, 2012.

[62] C. T. Sabeta, J. Bingham, and L. H. Nel, "Molecular epidemiology of canid rabies in Zimbabwe and South Africa," Virus Research, vol. 91, no. 2, pp. 203-211, 2003. 

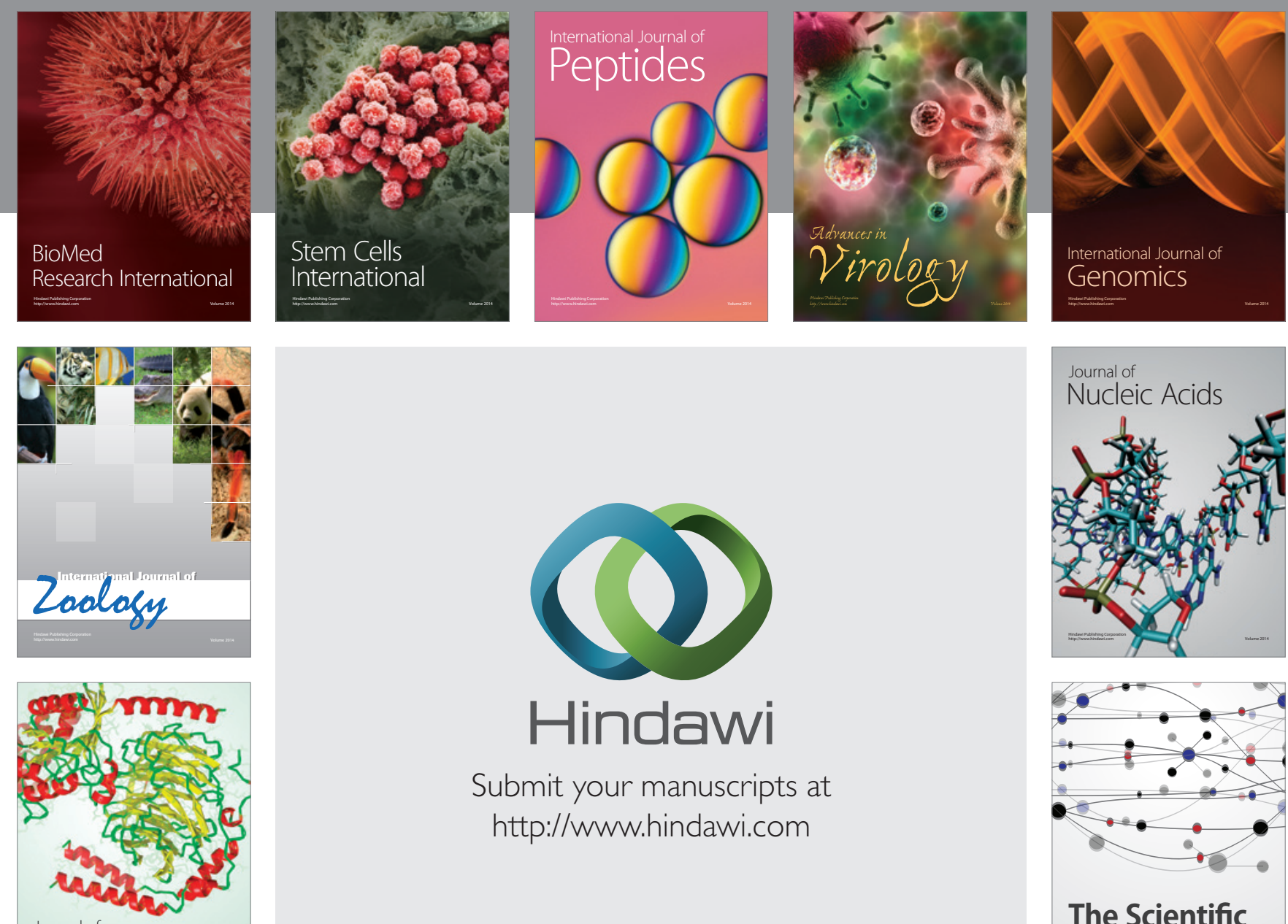

Submit your manuscripts at

http://www.hindawi.com

Journal of
Signal Transduction
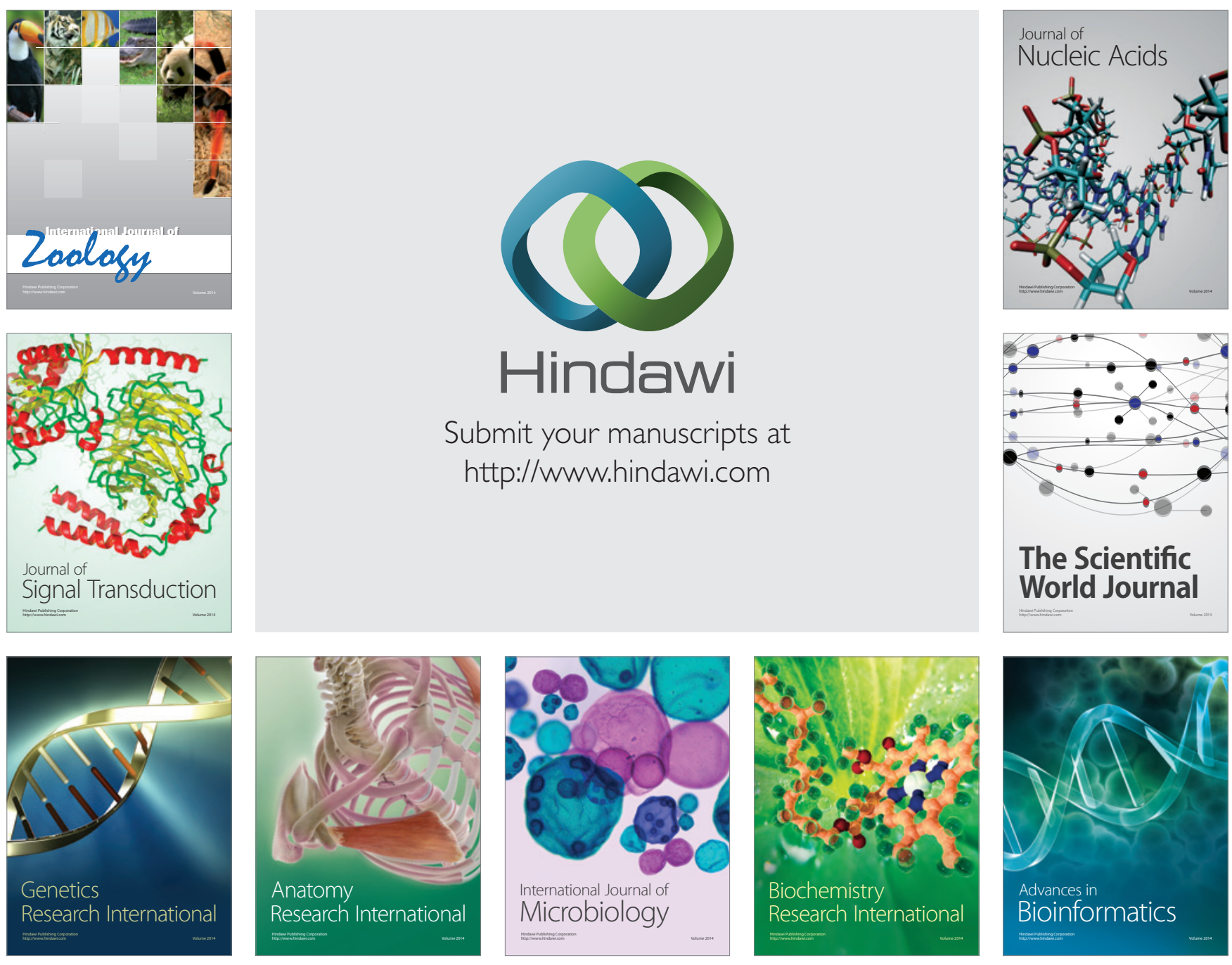

The Scientific World Journal
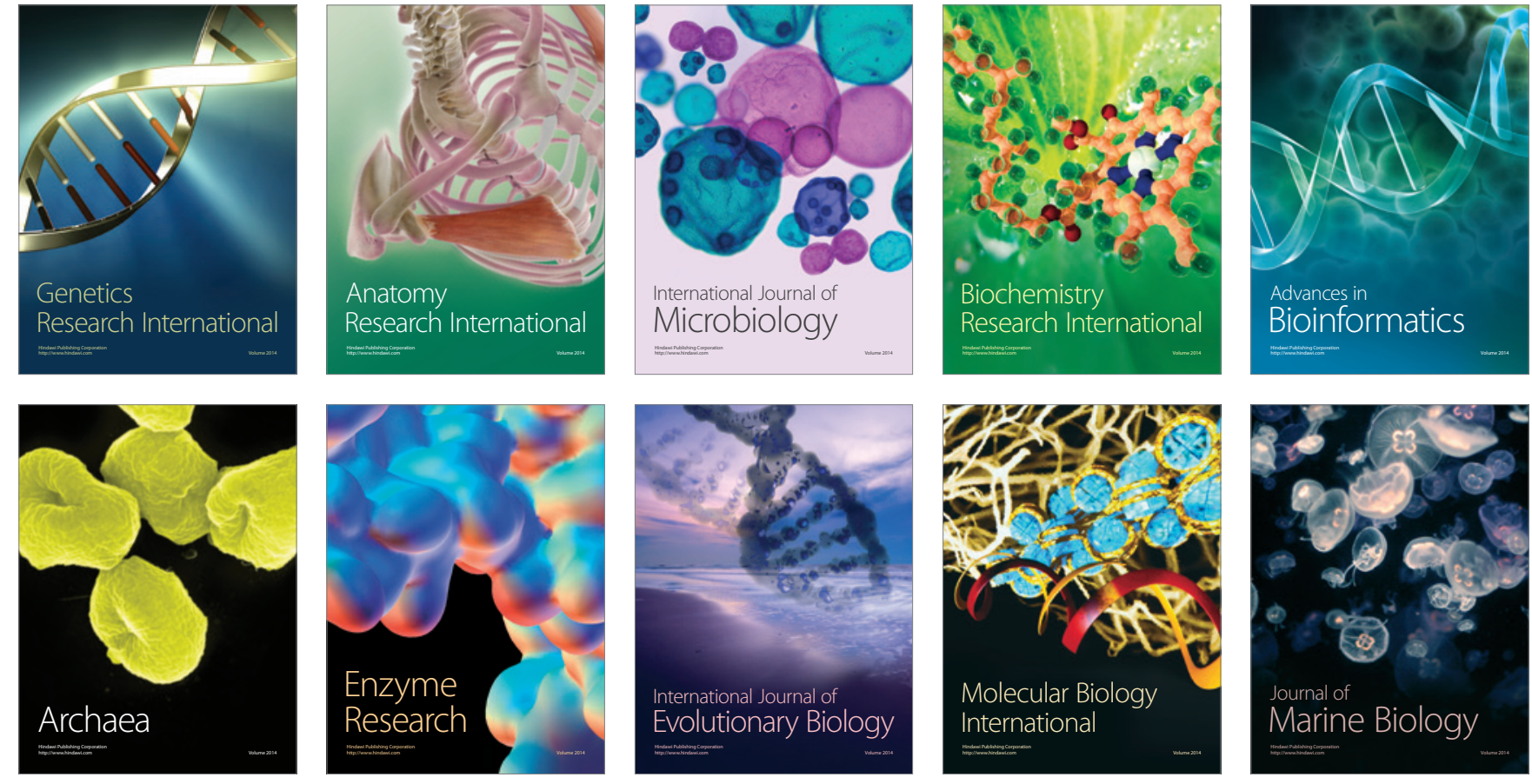